\title{
Color stability of a bulk-fill composite resin light-cured at different distances
}

\section{Christine Nagel BACKES(a) \\ Fabiana Mantovani Gomes FRANÇA $^{\text {(a) }}$ iD \\ Cecilia Pedroso TURSSI(a) iD \\ Flávia Lucisano Botelho do \\ AMARAL (a) \\ Roberta Tarkany BASTING(a) \\ (a)Faculdade São Leopoldo Mandic - SLMandic, School of Dentistry, Department of Restorative Dentistry, Campinas, SP, Brazil.}

Declaration of Interests: The authors certify that they have no commercial or associative interest that represents a conflict of interest in connection with the manuscript.

Corresponding Author: Roberta Tarkany Basting

E-mail: rbasting@yahoo.com

https://doi.org/10.1590/1807-3107bor-2020.vol34.0119

Submitted: January 24, 2020

Accepted for publication: July 27, 2020

Last revision: August 18, 2020
Abstract: The aim of this in vitro study was to evaluate the color stability of a bulk-fill (Filtek One Bulk Fill, 3M ESPE) and a conventional (Filtek Z350 XT, 3M ESPE) composite resin light-cured at different distances, before and after being submitted to staining with a coffee solution. Sixty specimens of each composite resin were prepared and light-cured at distances of 0, 2 and $4 \mathrm{~mm}$, using a LED light-curing unit (Valo, Ultradent). The specimens were separated $(n=10)$ for immersion in either distilled water or coffee solution (10 minutes a day for 8 days) to stimulate staining. Color evaluations were performed before and after immersion in the solutions, according to CIELab $(\triangle \mathrm{Eab})$, CIEDE2000 $(\triangle \mathrm{E} 00)$ and the Whiteness Index for Dentistry ( $\triangle \mathrm{WID})$. Kruskal Wallis and Dunn tests, Mann-Whitney tests and Wilcoxon test were applied $(\alpha=5 \%)$. The $\mathrm{a}^{*}$ value for conventional composite resin showed a significant increase after immersion in coffee and distilled water $(p<0.05)$. Both composite resins showed greater $b^{*}$ values when immersed in coffee than in distilled water, with no significant difference among the light-activation distances $(p>0.05)$. There was no significant difference for $L^{*}$ among the light-activation distances; both resins showed significant decrease in $L^{*}$ after immersion in coffee $(p<0.05)$. Color change $(\triangle E a b, \triangle E 00)$ and difference in whiteness $(\triangle W I D)$ were higher for conventional resin when immersed in the coffee solution at all the light-activation distances. Conventional composite resin presented a higher staining value than bulk-fill composite resin, regardless of the light-activation distance.

Keywords: Coffee; Color; Composite Resins.

\section{Introduction}

Composite resins have become the material of choice for aesthetic restorations, because they have the physical properties that reproduce the natural-looking beauty of teeth. ${ }^{1}$ In this respect, color stability is of utmost importance, since the staining of restorations by dyes of food and beverage consumption can impair their quality and aesthetic longevity. $2,3,4,5,6,7,8$

Composite resin staining may occur due to extrinsic and intrinsic factors. Among the intrinsic factors, the color change of the restoration from the oxidation of tertiary amines, the polymeric matrix, or the oxidation of residual methacrylate groups can be pointed out. These factors are dependent on the formulation and the quality of the light-activation of 
the resin-based material. ${ }^{5,6}$ Organic matrix content is also related to potential staining, and Bis-EMA (bisphenol A polyethylene glycol dimethacrylate) tends to react less favorably to pigment incorporation than UDMA (urethane dimethacrylate) and BisGMA (bisphenol-A glycidyl methacrylate), which have higher water sorption capacity because they are hydrophilic. The inorganic filler content may be influential, since possible spaces between the filler particles favor pigment deposition. ${ }^{7}$ The causes related to the extrinsic factors include color change by adsorption or dye absorption, as a result of contact with exogenous sources, such as an individual's diet. ${ }^{8}$

Some drinks in the diet of the population have greater potential to change the color of composite resins, such as coffee, tea, juices and wine. ${ }^{9,10}$ Coffee is a commonly consumed beverage and has strong potential to stain both dental structure and resin materials, because it has water-soluble dyes and polyphenols, such as tannin, caffeine and caffeic acid. Lower polarity causes the coffee pigments to have higher adsorption and dye penetration in the composite resin. ${ }^{1,3,5}$

Although bulk-fill resins have a monomeric chemical composition similar to that of conventional composite resins, ${ }^{11}$ it has been found that the degree of staining may increase as the thickness of the increment increases, since light-activation may not be effective at greater thicknesses. ${ }^{12}$ Bulk-fill composite resins are known to exhibit greater translucency than conventional resins, and facilitate light transmission. This allows better polymerization of the material when it is inserted in thicker increments, and the built-in monomers that trigger and control polymerization kinetics enable better polymerization thickness. ${ }^{11,13}$ However, the polymerization effectiveness related to greater insertion thicknesses of bulk-fill composite resins is inconsistent, and data are contradictory. ${ }^{14}$ This is especially true in situations where the resin may be exposed to the cavity, as in proximal surfaces of Class II cavities, in which the light needed to cure the layers in the cervical region can be minimized by the distance of light-activation. Although bulk-fill resin composites are mostly used for posterior restorations, problems related to color stability may make it difficult to decide whether to replace a restoration because of a color difference from the dental structure, especially in cervical regions. ${ }^{15}$ The more cervical the resin increment, the more intense the staining, owing to the greater distance of light-activation, and to the lower polymeric conversion. . $^{16,17,18,19}$

Therefore, the aim of this study was to evaluate the influence of the staining solution on the color stability of conventional composite and photo-cured bulk-fill resins at different distances. The null hypotheses to be evaluated were: a) the staining solution would not influence the color stability of conventional and bulk-fill resins; b) different light-activation distances would not influence the color stability of conventional and bulk-fill resins.

\section{Methodology}

\section{Specimens preparation}

The composite resins used in the study are specified in Table 1. A total of 60 specimens of each resin composite were randomly selected. They were divided into three groups of 20 specimens each according to light-activation distances ( 0,2 or $4 \mathrm{~mm})$. Afterwards, they were divided into two groups $(n=10)$, according to the immersion media: staining with distilled water (control) or with a coffee solution.

The specimens were prepared using rubber matrices $2 \mathrm{~mm}$ high and $10 \mathrm{~mm}$ internal diameter. The matrix was positioned on a glass plate, and the composite resin was inserted in a single increment into the matrix using spatulas (LM-Arte Modella, LM-Arte Condensa - LM-Dental, Parainen, Finland). Two strips of polyester were positioned at the ends (bottom and top) to eliminate bubbles and obtain a smooth surface. A glass coverslip was positioned on top of this, applying a weight of 500 grams for 30 seconds. Next, the coverslip was removed for light-activation of the composite resin.

The tip of the curing device was positioned according to the light-activation distances $(0,2$ or $4 \mathrm{~mm}$ ). These distances were chosen based on what seemed most commonly used in clinical procedures. Although a 0-mm curing distance is ideal to use in light-curing resin composites, clinical procedures do not always allow this approach..$^{20} \mathrm{~A} 2$-mm curing distance seems to be the best clinical case scenario. ${ }^{20}$ 
Table 1. Specification of materials under study.

\begin{tabular}{|c|c|c|c|}
\hline $\begin{array}{l}\text { Trademark / Manufacturer } \\
\text { (City, State, Country) / Lot }\end{array}$ & $\begin{array}{l}\text { Resin type } \\
\text { (Shade) }\end{array}$ & Composition (\% by weight) * & $\begin{array}{c}\text { Maximum increment } \\
\text { thickness/ light-activation } \\
\text { time of each increment } \\
\text { indicated by manufacturer }\end{array}$ \\
\hline $\begin{array}{l}\text { Filtek One Bulk Fill - 3M } \\
\text { ESPE / (St. Paul, MN - USA)/ } \\
\text { N691406 } \\
\text { N690323 } \\
\text { N891340 }\end{array}$ & $\begin{array}{l}\text { Single increment } \\
\text { bulk-fill } \\
\text { (A1) }\end{array}$ & $\begin{array}{c}\text { Treated Silanized Ceramics (60-70), Aromatic Urethane } \\
\text { Dimethacrylate (10-20), Ytterbium Fluoride (YbF3) (1-10), } \\
\text { Diurethane Dimethacrylate (UDMA) (1-10), Treated Silica (1- } \\
\text { 10) ), 1,12-Dodecane dimethacrylate (DDDMA) }(<5) \text {, Treated } \\
\text { silanized zirconia }(<5) \text {, Water }(<5) \text {, Modified methacrylate } \\
\text { monomer }(<1) \text {, Ethyl 4-dimethyl aminobenzoate (EDMAB) } \\
(<0.5) \text {, Benzotriazole }(<0.5)\end{array}$ & 4 to $5 \mathrm{~mm} / 10 \mathrm{~s}$ each face. \\
\hline $\begin{array}{l}\text { Filtek Z350 XT -3M ESPE/ } \\
\text { (St. Paul, MN - USA)/ } \\
591639 \\
688002 \\
856543 \\
734193\end{array}$ & $\begin{array}{l}\text { Conventional } \\
\text { (A1 Enamel) }\end{array}$ & $\begin{array}{l}\text { Treated Silanized Ceramics (60-80), Treated Silane Silica } \\
\text { (1-10), Diurethane Dimethacrylate (UDMA)(1-10), Bisphenol } \\
\text { A Polyethylene Glycol Diether Methacrylate (Bis-EMA) (1- } \\
\text { 10), Bisphenol Diglycidyl Ether Di-Methacrylate (BisGMA) } \\
\text { (1-10), Treated Silanized Zirconia (1-10), Polyethylene Glycol } \\
\text { Dimethacrylate }(<5) \text {, Triethylene Glycol Dimethacrylate } \\
\text { (TEGDMA) }(<5), 2,6 \text {-Di-tert butyl p-cresol }(<1)\end{array}$ & $2 \mathrm{~mm} / 20 \mathrm{~s}$ \\
\hline
\end{tabular}

*According to Manufacturer's Materials Safety Data Sheet (MSDS).

The irradiation ratio seems to be device-dependent at distances of 4 to $6 \mathrm{~mm},{ }^{21}$ but may compromise resin composite properties when these or farther distance are used..$^{20}$

The device tip was positioned over the polyester strip to obtain the distance of $0 \mathrm{~mm}$. The distances of 2 and $4 \mathrm{~mm}$ required that one or two other rubber matrices of $10 \mathrm{~mm}$ internal diameter and $2 \mathrm{~mm}$ high, respectively, be superimposed over the specimen in which the composite resin was inserted. This enabled obtaining the distance required for light-activation, performed by positioning the tip ( $9.75 \mathrm{~mm}$ diameter) of the LED light-curing device on the composite resin (Valo, Ultradent, South Jordan, USA / 395-400nm / $1000 \mathrm{~mW} / \mathrm{cm}^{2}$ ) for 20 seconds.

The specimens were fabricated and then removed from the rubber matrices, identified according to the surface that was cured and immersed in $3 \mathrm{~mL}$ of distilled water for 24 hours to be submitted to the initial color evaluation test. The resin surfaces were not finished or polished.

\section{Baseline color evaluation}

The specimens were fabricated and submerged in distilled water for 24 hours, and then removed from the storage medium and dried with sterile gauze. The baseline color analysis was performed by a single operator using a calibrated digital spectrophotometer (VITA Easyshade ${ }^{\circledR}$ Advance,
Vita Zahnfabrik, Bad Säckingen, Germany), in which the tip of the apparatus was placed perpendicular to the surface of the composite resin. The evaluations were performed using a 40-cm wide, 60 -cm long and 29-cm deep black box with a white inner background to prevent against the influence of external light. Color stability was measured by spectrophotometer, using the CIELab (Commission Internationale de L'Eclairage) color space coordinates. The measurements were performed by placing the specimens over a white background to observe the indication by the Vita Classical scale, and were obtained in duplicate. When the two readings of the Vita Classical scale coincided, the value obtained in the second reading of the $L^{*}, a^{*}$ and $b^{*}$ data was used. If the two readings did not match the same result for Vita Classical, a third measurement was performed to enable agreement between the two previous readings.

\section{Immersion media}

The specimens were immersed in different immersion media, namely distilled water or coffee solution. The coffee solution was prepared with 25 grams of coffee powder (Nescafé, NestléSA, Vevey, Switzerland) and $250 \mathrm{~mL}$ of distilled water. The coffee solution was prepared with boiling distilled water, and only when it reached room temperature $\left(24^{\circ} \mathrm{C} \pm 1^{\circ} \mathrm{C}\right)$ did the staining process begin. 
Half of the specimens made with each composite resin and light-activation distance were immersed in the coffee solution $(\mathrm{pH}=4.88)$. The other half represented the control group, which remained immersed in individual vials containing $3 \mathrm{~mL}$ of the distilled water $(\mathrm{pH}=5.65)$, at $37^{\circ} \mathrm{C}$ for 7 days. The specimens submitted to the coffee solution remained immersed in $3 \mathrm{~mL}$ of the dye solution for 10 minutes a day at $37^{\circ} \mathrm{C}$, under constant agitation on a shaker table (SK 0330-Pro, Dragonlab Laboratory Instruments Limited, Beijing, China). They were then washed with distilled water for 5 seconds, and remained immersed in distilled water. This cycle was repeated for 8 days, according to Borges et al. ${ }^{3}$

\section{Final color evaluation}

The specimens remained for another 24 hours in relative humidity following the staining process, and were subsequently re-evaluated for color stability, using the same protocols described previously.

The $\Delta \mathrm{E}_{\mathrm{ab}}$ values were calculated by comparing the baseline and final values ( 48 hours after the end of treatment), considering the values of $\Delta \mathrm{L}^{*}, \Delta \mathrm{a}^{*}$ and $\Delta \mathrm{b}^{*}$ between the start and end times of the evaluation for each treatment. Next, the $\Delta \mathrm{E}_{\mathrm{ab}}$ (color change) was calculated using the following mathematical formula: ${ }^{21}$ $\Delta \mathrm{E}_{\mathrm{ab}}=\sqrt{ }(\Delta \mathrm{L})^{2}+(\Delta \mathrm{a})^{2}+(\Delta \mathrm{b})^{2} ; \Delta \mathrm{L}^{*}=\mathrm{L}^{*}$ final - L*initial; $\Delta a^{*}=a^{*}$ final - $a^{*}$ initial; $\Delta b^{*}=b^{*}$ final - $b^{*}$ initial. The perceptibility and acceptability thresholds considered for $\Delta \mathrm{E}_{\mathrm{ab}}$ were 1.2 and 2.7, respectively. ${ }^{22,23}$ Color change was also evaluated by CIEDE2000 $\left(\Delta \mathrm{E}_{00}\right)$, which uses $h$ (hue) and $C$ (chroma) values. ${ }^{24} \Delta \mathrm{E}_{00}$ values of 0.8 and 1.8 were adopted as the perceptibility and acceptability thresholds. ${ }^{22}$

Difference in whiteness was also calculated using the whiteness index for dentistry $\left(\mathrm{WI}_{\mathrm{D}}\right)$, in which the $\mathrm{L}^{*}$, $\mathrm{a}^{*}$ and $b^{*}$ parameters are used in the following equation: ${ }^{25}$ $\mathrm{WI}_{\mathrm{D}}=0.511 \mathrm{~L}^{*}-2.324 \mathrm{a}^{*}-1.100 \mathrm{~b}^{*}$. Differences in $\mathrm{WI}_{\mathrm{D}}$ between initial and final evaluations were also evaluated to obtain $\left(\Delta \mathrm{WI}_{\mathrm{D}}\right)$, whereas the thresholds for $\Delta \mathrm{WI} \mathrm{I}_{\mathrm{D}}$ were 0.72 for perceptibility and 2.60 for acceptability. ${ }^{26}$

\section{Statistical analysis}

After exploratory analysis, the data were analyzed by the nonparametric Kruskal Wallis and Dunn tests for comparison of the three distances, Mann
Whitney for comparison of the resins and of the immersion solutions, and Wilcoxon test (paired) for comparison of the time periods. Analyses were performed using a software program, ${ }^{27}$ considering a significance level of $5 \%$.

\section{Results}

$\mathrm{L}^{*}$ baseline values revealed that the conventional resin presented higher luminosity than the bulk-fill resin. After immersion in coffee and distilled water, the resins showed no difference, considering that they had lower $L^{*}$ values after coffee immersion and higher values after immersion in distilled water (Table 2). There was also an increase in the $\mathrm{a}^{*}$ values for conventional composite resin, regardless of the distance (Table 3 ). An increase in the $a^{*}$ value occurred in the bulk-fill resin only when it was immersed in coffee $(\mathrm{p}<0.05)$, differing significantly from when it was immersed in water $(p<0.05)$. Conventional composite resin presented less negative or more positive (reddish) values after immersion in water or coffee, respectively, than bulk-fill resin, except at a distance of $4 \mathrm{~mm}$ when immersed in coffee.

At baseline, the $b^{*}$ value was significantly higher in the bulk-fill composite resin. Despite an increase in the $b^{*}$ value after coffee immersion, and a decrease after distilled water immersion, there was no statistical difference between the resins after the respective immersions (Table 4).

The conventional resin showed a higher color change $\left(\Delta \mathrm{E}_{\mathrm{ab}}, \Delta \mathrm{E}_{00}\right)$ and higher difference in $\mathrm{WI}_{\mathrm{D}}$ $\left(\Delta \mathrm{WI}_{\mathrm{D}}\right)$ than the bulk-fill resin when immersed in coffee at all light-activation distances (Table 5). Although the conventional resin presented a higher color change $\left(\Delta \mathrm{E}_{\mathrm{ab}}\right)$ when immersed in coffee than in distilled water, both resins showed higher color change for $\Delta \mathrm{E}_{00}$ and higher difference in whiteness $\left(\Delta \mathrm{WI}_{\mathrm{D}}\right)$ in coffee than in distilled water at all lightactivation distances $(\mathrm{p}<0.05) . \Delta \mathrm{WI}_{\mathrm{D}}$ was also higher for the conventional resin than the bulk-fill resin when immersed in distilled water, and showed a whiter effect when immersed in this solution (Table 5). Figure shows the specimens before and after coffee staining at all curing distances. 
Table 2. Median (minimum value; maximum value) of $\mathrm{L}^{*}$ value as a function of composite resin, immersion medium, light-activation distance and evaluation time periods.

\begin{tabular}{|c|c|c|c|c|c|}
\hline \multirow{2}{*}{ Time } & \multirow{2}{*}{ Immersion } & \multirow{2}{*}{ Resin } & \multicolumn{3}{|c|}{ Light-activation distance } \\
\hline & & & $0 \mathrm{~mm}$ & $2 \mathrm{~mm}$ & $4 \mathrm{~mm}$ \\
\hline \multirow{4}{*}{ Baseline } & \multirow{2}{*}{ Coffee } & Conventional & $86.20(84.40 ; 88.10) \mathrm{Aa}$ & $85.30(84.10 ; 87.80) \mathrm{Aa}$ & $86.50(83.60 ; 87.30) \mathrm{Aa}$ \\
\hline & & Bulk-fill & 84.05 (81.90; 85.30) Ab & $83.10(81.30 ; 85.50) \mathrm{Ab}$ & $83.50(82.00 ; 84.60) \mathrm{Ab}$ \\
\hline & \multirow{2}{*}{ Distilled water } & Conventional & $84.60(83.30 ; 86.60) \mathrm{Aa}$ & $84.45(82.40 ; 86.60) \mathrm{Aa}$ & $85.60(82.70 ; 87.10) \mathrm{Aa}$ \\
\hline & & Bulk-fill & $83.40(81.70 ; 85.00) \mathrm{Ab}$ & $83.15(82.10 ; 86.40) \mathrm{Ab}$ & $83.00(81.90 ; 85.10) \mathrm{Ab}$ \\
\hline \multirow{4}{*}{$\begin{array}{l}\text { After } \\
\text { immersion }\end{array}$} & \multirow{2}{*}{ Coffee } & Conventional & $\$ 82.80(81.40 ; 84.70) \mathrm{Aa}$ & $\$ 82.35(81.30 ; 84.40) \mathrm{Aa}$ & $\$ 82.15(79.90 ; 83.40) \mathrm{Aa}$ \\
\hline & & Bulk-fill & $\$ 82.20(79.90 ; 83.90) \mathrm{Aa}$ & $\$ 81.95(80.50 ; 84.40) \mathrm{Aa}$ & $\$ 82.00(79.40 ; 84.00) \mathrm{Aa}$ \\
\hline & \multirow{2}{*}{ Distilled water } & Conventional & ${ }^{* \$ 85.60}(83.10 ; 88.40) \mathrm{Aa}$ & *\$86.30 (84.10; 88.00) Aa & ${ }^{* \$ 86.30}(84.30 ; 88.90) \mathrm{Aa}$ \\
\hline & & Bulk-fill & ${ }^{* \$ 84.95}(82.70 ; 85.70) \mathrm{Aa}$ & ${ }^{* \$ 84.85}(84.10 ; 86.90) \mathrm{Ab}$ & ${ }^{* s} 84.85(84.00 ; 86.40) \mathrm{Ab}$ \\
\hline
\end{tabular}

*Differs from the group immersed in coffee under the same resin conditions, distance and time ( $x \leq 0.05)$. ${ }^{\$}$ Differs from baseline under the same resin, distance and immersion conditions $(p \leq 0.05)$. Medians followed by distinct letters (uppercase horizontally, comparing distances for each resin; lowercase vertically, comparing resin for each distance) at each time period (baseline or after immersion) differ from one another $(p \leq 0.05)$.

Table 3. Median (minimum value; maximum value) of a* value as a function of composite resin, immersion medium, light-activation distance and evaluation time periods.

\begin{tabular}{|c|c|c|c|c|c|}
\hline \multirow{2}{*}{ Time } & \multirow{2}{*}{ Immersion } & \multirow{2}{*}{ Resin } & \multicolumn{3}{|c|}{ Light-activation distance } \\
\hline & & & $0 \mathrm{~mm}$ & $2 \mathrm{~mm}$ & $4 \mathrm{~mm}$ \\
\hline \multirow{4}{*}{ Baseline } & \multirow{2}{*}{ Coffee } & Conventional & $-1.40(-1.50 ;-0.80) \mathrm{Aa}$ & $-1.40(-1.50 ;-0.90) \mathrm{Aa}$ & $-1.40(-1.50 ;-1.00) \mathrm{Aa}$ \\
\hline & & Bulk-fill & $-1.95(-2.20 ;-1.10) \mathrm{Ab}$ & $-1.20(-2.20 ;-1.10) \mathrm{Aa}$ & $-1.20(-2.20 ;-1.00) \mathrm{Aa}$ \\
\hline & \multirow{2}{*}{ Distilled water } & Conventional & $-1.50(-1.60 ;-1.40) \mathrm{Ab}$ & $-1.40(-1.60 ;-1.10) \mathrm{Aa}$ & $-1.40(-1.50 ;-1.30) \mathrm{Ab}$ \\
\hline & & Bulk-fill & $-1.25(-2.00 ;-1.10) \mathrm{Aa}$ & $-1.25(-1.80 ;-1.00) \mathrm{Aa}$ & $-1.25(-1.50 ;-1.00) \mathrm{Aa}$ \\
\hline \multirow{4}{*}{$\begin{array}{l}\text { After } \\
\text { immersion }\end{array}$} & \multirow{2}{*}{ Coffee } & Conventional & ${ }^{\$} 0.80(0.20 ; 1.50) \mathrm{Aa}$ & ${ }^{\$} 0.75(0.50 ; 1.70) \mathrm{Aa}$ & ${ }^{\$} 0.40(0.10 ; 1.00) \mathrm{Aa}$ \\
\hline & & Bulk-fill & $\$-0.25(-0.70 ; 0.70) \mathrm{Ab}$ & $\$ 0.10(-0.70 ; 1.20) \mathrm{Ab}$ & $\$ 0.20(-0.80 ; 1.20) \mathrm{Aa}$ \\
\hline & \multirow{2}{*}{ Distilled water } & Conventional & ${ }^{*}-0.85(-1.00 ;-0.60) \mathrm{Aa}$ & ${ }^{* \$}-0.70(-0.90 ;-0.50) \mathrm{Aa}$ & ${ }^{* \$}-0.75(-0.90 ;-0.50) \mathrm{Aa}$ \\
\hline & & Bulk-fill & ${ }^{*}-1.25(-2.00 ;-0.90) \mathrm{Ab}$ & ${ }^{*}-1.15(-1.50 ;-1.00) \mathrm{Ab}$ & ${ }^{*}-1.15(-1.50 ;-0.90) \mathrm{Ab}$ \\
\hline
\end{tabular}

*Differs from the group immersed in coffee under the same resin conditions, distance and time $(p \leq 0.05)$. ${ }^{\$}$ Differs from baseline under the same resin, distance and immersion conditions ( $\mathrm{x} \leq 0.05$ ). Medians followed by distinct letters (uppercase horizontally, comparing distances for each resin; lowercase vertically, comparing resin for each distance) at each time period (baseline or after immersion) differ from one another $(p \leq 0.05)$.

Table 4. Median (minimum value; maximum value) of $b^{*}$ value as a function of composite resin, immersion medium, light-activation distance and moment of evaluation.

\begin{tabular}{|c|c|c|c|c|c|}
\hline \multirow{2}{*}{ Time } & \multirow{2}{*}{ Immersion } & \multirow{2}{*}{ Resin } & \multicolumn{3}{|c|}{ Light-activation distance } \\
\hline & & & $0 \mathrm{~mm}$ & $2 \mathrm{~mm}$ & $4 \mathrm{~mm}$ \\
\hline \multirow{4}{*}{ Baseline } & \multirow{2}{*}{ Coffee } & Conventional & $15.10(14.50 ; 15.80) \mathrm{Ab}$ & $15.10(14.60 ; 15.80) \mathrm{Ab}$ & $15.30(14.60 ; 16.60) \mathrm{Ab}$ \\
\hline & & Bulk-fill & $16.80(15.20 ; 17.70) \mathrm{Aa}$ & $16.55(15.40 ; 18.00) \mathrm{Aa}$ & $16.35(15.60 ; 18.30) \mathrm{Aa}$ \\
\hline & \multirow{2}{*}{ Distilled water } & Conventional & $15.45(15.00 ; 16.40) \mathrm{Ab}$ & $15.65(15.00 ; 16.30) \mathrm{Ab}$ & $15.80(15.10 ; 16.50) \mathrm{Ab}$ \\
\hline & & Bulk-fill & $16.45(14.60 ; 18.00) \mathrm{Aa}$ & $16.50(16.10 ; 17.20) \mathrm{Aa}$ & $16.65(15.60 ; 17.20) \mathrm{Aa}$ \\
\hline \multirow{4}{*}{$\begin{array}{l}\text { After } \\
\text { immersion }\end{array}$} & \multirow{2}{*}{ Coffee } & Conventional & $\$ 18.15(16.30 ; 19.50) \mathrm{Aa}$ & $\$ 17.15(16.60 ; 22.20) \mathrm{Aa}$ & $\$ 17.25(15.40 ; 19.70) \mathrm{Aa}$ \\
\hline & & Bulk-fill & $\$ 18.05(16.10 ; 18.70) \mathrm{Aa}$ & $\$ 17.70(15.70 ; 18.40) \mathrm{Aa}$ & $\$ 17.30(15.70 ; 18.30) \mathrm{Aa}$ \\
\hline & \multirow{2}{*}{ Distilled water } & Conventional & ${ }^{* s} 14.40(12.20 ; 15.70) \mathrm{Ab}$ & ${ }^{* \$} 14.30(12.10 ; 16.40) \mathrm{Ab}$ & ${ }^{* \$} 14.40(12.10 ; 16.00) \mathrm{Ab}$ \\
\hline & & Bulk-fill & *\$15.65 (12.80; 16.30) Aa & ${ }^{* \$} 15.45(14.40 ; 16.70) \mathrm{Aa}$ & ${ }^{* \$} 15.40(14.70 ; 17.10) \mathrm{Aa}$ \\
\hline
\end{tabular}

${ }^{*}$ Differs from the group immersed in coffee under the same resin conditions, distance and time $(p \leq 0.05)$. ${ }^{\$}$ Differs from baseline under the same resin, distance and immersion conditions ( $p \leq 0.05$ ). Medians followed by distinct letters (uppercase horizontally, comparing distances with each resin; lowercase vertically, comparing resins with each distance) at each time period (baseline or after immersion) differ from one another $(p \leq 0.05)$. 
Table 5. Median (minimum value; maximum value) color change $\left(\Delta \mathrm{E}_{\mathrm{ab}}\right.$ and $\left.\Delta \mathrm{E}_{00}\right)$ and difference in whiteness $(\Delta \mathrm{WI})$, according to composite resin, immersion medium, and light-activation distance.

\begin{tabular}{|c|c|c|c|c|c|}
\hline \multirow{2}{*}{$\begin{array}{l}\text { Color } \\
\text { change }\end{array}$} & \multirow{2}{*}{ Immersion } & \multirow{2}{*}{ Resin } & \multicolumn{3}{|c|}{ Light-activation distance } \\
\hline & & & $0 \mathrm{~mm}$ & $2 \mathrm{~mm}$ & $4 \mathrm{~mm}$ \\
\hline \multirow{4}{*}{$\Delta \mathrm{E}_{\mathrm{ab}}$} & \multirow{2}{*}{ Coffee } & Conventional & $4.64(2.20 ; 7.20) \mathrm{Aa}$ & $4.46(3.54 ; 8.68) \mathrm{Aa}$ & $4.93(2.36 ; 6.20) \mathrm{Aa}$ \\
\hline & & Bulk-fill & $2.45(1.93 ; 4.72) \mathrm{Ab}$ & $1.90(1.19 ; 4.93) \mathrm{Ab}$ & $2.56(1.45 ; 4.25) \mathrm{Ab}$ \\
\hline & \multirow{2}{*}{ Distilled water } & Conventional & *2.00 $(0.64 ; 3.49) \mathrm{Aa}$ & *2.19 $(0.70 ; 3.54) \mathrm{Aa}$ & *2.64 $(0.87 ; 3.54) \mathrm{Aa}$ \\
\hline & & Bulk-fill & ${ }^{*} 2.00(0.62 ; 2.90) \mathrm{Aa}$ & $1.99(1.05 ; 2.63) \mathrm{Aa}$ & $2.10(0.51 ; 3.74) \mathrm{Aa}$ \\
\hline \multirow{4}{*}{$\Delta \mathrm{E}_{00}$} & \multirow{2}{*}{ Coffee } & Conventional & $3.47(1.88 ; 4.91) \mathrm{Aa}$ & $3.52(3.06 ; 5.64) \mathrm{Aa}$ & $3.76(2.21 ; 4.42) \mathrm{Aa}$ \\
\hline & & Bulk-fill & $2.24(1.86 ; 3.41) \mathrm{Ab}$ & $1.92(1.35 ; 3.99) \mathrm{Ab}$ & $2.34(1.46 ; 3.62) \mathrm{Ab}$ \\
\hline & \multirow{2}{*}{ Distilled water } & Conventional & ${ }^{*} 1.41(0.73 ; 2.34) \mathrm{Aa}$ & ${ }^{*} 1.47(0.76 ; 2.40) \mathrm{Aa}$ & ${ }^{*} 1.74(0.72 ; 2.35) \mathrm{Aa}$ \\
\hline & & Bulk-fill & ${ }^{*} 1.25(0.36 ; 1.87) \mathrm{Aa}$ & ${ }^{*} 1.23(0.7 ; 1.65) \mathrm{Aa}$ & ${ }^{*} 1.37(0.32 ; 2.45) \mathrm{Aa}$ \\
\hline \multirow{4}{*}{$\Delta \mathrm{WI}_{\mathrm{D}}$} & \multirow{2}{*}{ Coffee } & Conventional & $-9.53(-12.33 ;-4.82) \mathrm{Ab}$ & $-8.49(-15.86 ;-7.66) \mathrm{Ab}$ & $-8.00(-10.54 ;-4.74) \mathrm{Ab}$ \\
\hline & & Bulk-fill & $-5.38(-9.36 ;-4.77) \mathrm{Aa}$ & $-4.33(-9.10 ;-2.22) \mathrm{Aa}$ & $-5.06(-8.25 ;-2.69) \mathrm{Aa}$ \\
\hline & \multirow{2}{*}{ Distilled water } & Conventional & $* 0.27(-1.39 ; 1.94) \mathrm{Ab}$ & ${ }^{*} 0.51(-1.83 ; 2.27) \mathrm{Ab}$ & ${ }^{*} 0.84(-0.87 ; 2.51) \mathrm{Ab}$ \\
\hline & & Bulk-fill & ${ }^{*} 2.25(0.38 ; 2.68) \mathrm{Aa}$ & ${ }^{*} 1.98(-0.05 ; 2.84) \mathrm{Aa}$ & ${ }^{*} 1.96(0.67 ; 2.98) \mathrm{Aa}$ \\
\hline
\end{tabular}

*Differs from the group immersed in coffee under the same resin conditions, distance and time ( $\mathrm{p} \leq 0.05)$. Medians followed by distinct letters (uppercase horizontally, comparing distances with each resin; lowercase vertically, comparing resins with each distance) at each time period (baseline or after immersion) differ from one another ( $p \leq 0.05)$.
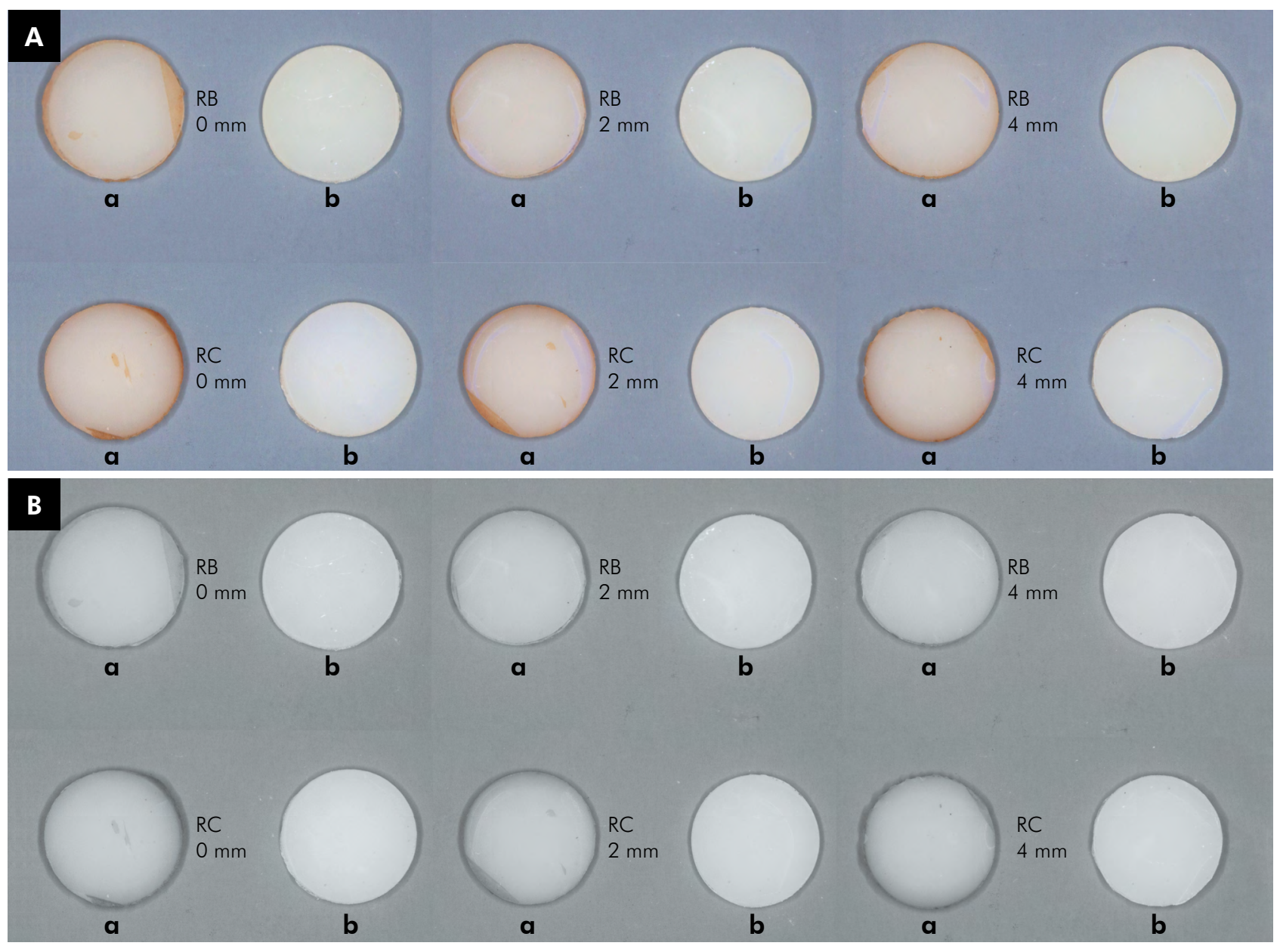

Figure. Specimens before and after coffee staining at all curing distances (A - color; B - black and white; RB = resin composite bulk-fill; $R C=$ resin composite conventional; $b=$ before coffee staining; $a=$ after coffee staining). 


\section{Discussion}

Although conventional and bulk-fill resins have different recommended maximum increment thickness to provide better polymerization at greater distances from the activating light source, ${ }^{11,13,28,29}$ both have similar percentages of inorganic component weight, namely $78.5 \%$ filler for conventional composite resin and $76.5 \%$ filler for bulk-fill composite resins. ${ }^{7}$ Despite modifications in the physical properties of bulk-fill resinssuch as greater translucency-and the addition of polymerization modulators, the composition of both resins studied does not differ considerably. ${ }^{11,13,30}$

Although the same color (A1) of conventional and bulk-fill composite resins was used in the present study, differences were observed in the baseline for $L^{*}$ values, that is, the conventional resin was brighter compared to the bulk-fill resin, regardless of light-activation distance. Bulk-fill resins have a relatively lower filler amount and a larger particle size than conventional resins. This is related to the direct influence on the translucency of the material, which allows a greater amount of light to penetrate the thickness of the material, thus making the values for the bulk-fill composite resins lower. ${ }^{14}$

Increased luminosity was observed for both resins after immersion in water. Some factors determine the extent to which the material will be affected by the aqueous medium, including sorption and solubility, crosslinking density, hydrophilicity, and the network porosity of polymeric materials, ${ }^{30}$ thus confirming that water immersion at different time periods may interfere with the color stability of composites. Water molecule affinity to the hydrophilic groups of the polymeric chain causes them to bind together, thus causing polymer swelling and plasticization. The solvent diffuses within the polymeric chain, causing separation of these chains and expansion of the network. ${ }^{30}$ Thus, alterations in water sorption may explain the change in the luminosity of the materials. This resulted in positive mean values for $\Delta \mathrm{WI}_{\mathrm{D}}$, and in reduced mechanical properties and changes in physical properties, making the materials brighter.
On the other hand, immersion in coffee solution led to a decrease in the luminosity of both resins, which may be attributed to the presence of darkcolored pigments in the solution. The staining of the resin with coffee pigments seems to occur not only on the surface of the material but also in depth, owing to dye adsorption and absorption in the resin matrix material. ${ }^{6}$

Regarding parameter a*, an increase was observed in the red band value for the composite resins, since the values became less negative (or positive) when immersed in coffee. It has been reported that the composition of the organic phase may favor pigment incorporation. ${ }^{31}$ Higher pigmentation has been observed in resins containing triethylene glycol dimethacrylate (TEGDMA), which has more hydrophilic characteristics and higher water absorption capacity. ${ }^{31}$ Both the conventional resin and the bulk-fill resin tested have hydrophilic monomers in their composition, such as UDMA. However, only conventional resin has TEGDMA, which is characterized by a more elution-prone monomer. ${ }^{31}$ This may better explain its greater ability to incorporate pigments, although both resins have shown staining ability.

As for the conventional resin, an a* increase was also observed when it was immersed in water, probably attributed to its higher water sorption property. ${ }^{32}$ Water sorption and solubility of composites in a specified medium are materialdependent, and highly affected by the amount of filler and properties of the polymer matrix, such as hydrophilicity/hydrophobicity. ${ }^{31}$ Sorption values are negatively correlated with the amount of resin filler. ${ }^{31}$ The higher the volume in weight of the filler, the lower the volume of the polymer matrix, resulting in less water absorption, thus confirming that this is a phenomenon associated with the polymer phase. ${ }^{31}$ Sorption may also occur in composites with a high filler and low matrix interface, since it provides a means of water diffusion and progressive degradation of the material. ${ }^{31,33}$ It is suggested that the hydrolytic degradation of the interface between resinous components and the inorganic portion may modify the way light is dissipated by filler particles. 
As for the $b^{*}$ value, all the resins at all the distances differed significantly from the baseline after immersion in water or coffee. However, coffee immersion promoted a more significant increase in $b^{*}$ than water immersion. It is known that coffee has yellowish pigments, associated with the susceptibility of resin staining by these pigments, in addition to water sorption capacity and hydrophilicity of the matrix resin. ${ }^{31,32}$ Water acts as a vehicle for pigment penetration into the resin matrix, whereas the filler particles do not absorb water; therefore, a higher amount of resinous matrix, especially that containing more hydrophilic monomers, promotes higher water sorption $^{24,26}$; this may lead to a greater color change. ${ }^{4}$

Coffee also has significant amounts of gallic acid, which favors composite pigmentation. ${ }^{12}$ The adsorption and absorption of pigments in the organic matrix of the material-not easily removed by brushing, finishing or polishing-directly impact the values obtained for the color change $\left(\triangle \mathrm{E}_{\mathrm{ab}}, \triangle \mathrm{E}_{00}\right)$ and for the difference in whiteness $\left(\triangle \mathrm{WI} \mathrm{I}_{\mathrm{D}}\right)$. For this reason, the first null hypothesis was rejected, since the staining solution influenced the color stability properties of the conventional and bulkfill resins. Furthermore, when immersed in coffee, the conventional composite resin presented higher $\triangle \mathrm{E}_{\mathrm{ab},}, \triangle \mathrm{E}_{00}$ and $\triangle \mathrm{WI} \mathrm{I}_{\mathrm{D}}$ values than the bulk-fill resin at all light-activation distances. These differences are probably related to the organic matrix composition, ${ }^{7}$ since TEGDMA and Bis-GMA are hydrophilic monomers, which are more susceptible to pigment incorporation. This may explain the results of $\triangle \mathrm{E}_{\mathrm{ab}}$, since conventional resin has these monomers in its composition, corroborating the findings of Mansouri and Zidan. ${ }^{34}$ The results presented values above the limit of 2.7,22,23 which is considered clinically acceptable. ${ }^{22}$ However, the color change obtained by the CIEDE2000 formula $\left(\Delta \mathrm{E}_{00}\right)$ is better correlated with visual perception than the CIELAB. ${ }^{22}$ In this study, the $\Delta \mathrm{E}_{00}$ values for immersion in coffee solution for both the resins and the light-activation distances (all median values above 1.92) were higher than the perceptibility and acceptability thresholds, ${ }^{22}$ showing that immersion in coffee caused clinically perceptible color changes. Furthermore, $\triangle W I_{D}$ mean values were also above the threshold limits for perceptibility and acceptability when the resins were immersed in the coffee solution. However, these values were lower than the acceptable values when both resins were immersed in distilled water, and higher than the threshold limit for perceptibility when the conventional resin was light-cured at a $4-\mathrm{mm}$ distance, and the bulk-fill resin, at all distances. ${ }^{26}$

Regarding the light-activation distances, there was no influence in the color change in the present study. This leads to the acceptance of the second null hypothesis. However, another study ${ }^{12}$ shows that bulkfill resins have significantly higher staining power when the thickness increases; this may influence the lower longevity of restorations. A curing unit that provides sufficient energy for activation of resinspecific primers may minimize the effects of the light-activation distance, ${ }^{35}$ specifically at the evaluated distances, which did not exceed $4 \mathrm{~mm} .{ }^{20,21}$ The LED light-curing unit used herein is a high-power unit, with three blue LEDs and one violet LED on its tip. This resulted in great effectiveness in exciting various types of photoinitiators. ${ }^{36}$ Furthermore, the total irradiance output could be the same for the three different distances, because all the light output from the light-curing unit was conserved by using black rubber matrices. These factors could influence the color difference values.

Blue LEDs are more powerful than violet ones, and provide much deeper light penetration, thus producing more complete polymerization of both conventional and bulk-fill composite resins ${ }^{37}$ Overall, bulk-fill resins exhibit greater translucency compared with conventional resins. Since light transmission is closely connected to the opacity of the material, the filler/matrix ratio in these resins is low, favoring light dissipation and increasing the degree of conversion. ${ }^{20,21,38}$ However, even with no color change differences in the composite resins in relation to the light-activation distances, the light transmission rate may have affected other material properties, such as hardness and degree of conversion. Furthermore, the findings of this study are limited to the 2-mm thickness of the resin composites used, leaving unknown what the effect would be for much thicker samples, in a range up to $5 \mathrm{~mm}$, as is indicated for bulk-fill resins. Similarly, only one color was 
evaluated, and no finishing or polishing procedures were applied to the surface of the samples; this also could have influenced the results. Therefore, future studies should be performed to investigate these properties.

\section{Conclusions}

The conventional resin composite showed higher staining when immersed in coffee than the bulk-fill resin, regardless of the light-activation distance.

\section{References}

1. Telang A, Narayana IH, Madhu KS, Kalasaiah D, Ramesh P, Nagaraja S. Effect of staining and bleaching on color stability and surface roughness of three resin composites: an in vitro study. Contemp Clin Dent. 2018 Jul-Sep;9(3):452-6. https://doi.org/10.4103/ccd.ccd_297_18

2. Tuncer $D$, Karaman E, Firat E. Does the temperature of beverages affect the surface roughness, hardness, and color stability of a composite resin? Eur J Dent. 2013 Apr;7(2):165-71. https://doi.org/10.4103/1305-7456.110161

3. Borges AB, Caneppele TM, Luz M, Pucci CR, Torres CR. Color stability of resin used for caries infiltration after exposure to different staining solutions. Oper Dent. 2014 Jul-Aug;39(4):433-40. https://doi.org/10.2341/13-150-L

4. Poggio C, Ceci M, Beltrami R, Mirando M, Wassim J, Colombo M. Color stability of esthetic restorative materials: a spectrophotometric analysis. Acta Biomater Odontol Scand. 2016 Aug;2(1):95-101. https://doi.org/10.1080/23337931.2016.1217416

5. Um CM, Ruyter IE. Staining of resin-based veneering materials with coffee and tea. Quintessence Int. 1991 May;22(5):377-86.

6. Ertaş E, Güler AU, Yücel AÇ, Köprülü H, Güler E. Color stability of resin composites after immersion in different drinks. Dent Mater J. 2006 Jun;25(2):371-6. https://doi.org/10.4012/dmj.25.371

7. Mailart MC, Rocha RS, Contreras SC, Torres CR, Borges AB, Caneppele TM. Effects of artificial staining on bulk-filled resin composites. Am J Dent. 2018 Jun;31(3):144-8.

8. Guler AU, Yilmaz F, Kulunk T, Guler E, Kurt S. Effects of different drinks on stainability of resin composite provisional restorative materials. J Prosthet Dent. 2005 Aug;94(2):118-24. https://doi.org/10.1016/i.prosdent.2005.05.004

9. Borges MG, Soares CJ, Maia TS, Bicalho AA, Barbosa TP, Costa HL, et al. Effect of acidic drinks on shade matching, surface topography, and mechanical properties of conventional and bulk-fill composite resins. J Prosthet Dent. 2019 May;121(5):868.el-8. https://doi.org/10.1016/i.prosdent.2019.02.006

10. Choi JW, Lee MJ, Oh SH, Kim KM. Changes in the physical properties and color stability of aesthetic restorative materials caused by various beverages. Dent Mater J. 2019 Feb;38(1):33-40. https://doi.org/10.4012/dmi.2017-247

11. Ilie N, Bucuta S, Draenert M. Bulk-fill resin-based composites: an in vitro assessment of their mechanical performance. Oper Dent. 2013 Nov-Dec;38(6):618-25. https://doi.org/10.2341/12-395-L

12. Shamszadeh S, Sheikh-AI-Eslamian SM, Hasani E, Abrandabadi AN, Panahandeh N. Color stability of the bulk-fill composite resins with different thickness in response to coffee/water immersion. Int J Dent. 2016;2016:7186140. https://doi.org/10.1155/2016/7186140

13. Garcia D, Yaman P, Dennison J, Neiva G. Polymerization shrinkage and depth of cure of bulk fill flowable composite resins. Oper Dent. 2014 Jul-Aug;39(4):441-8. https://doi.org/10.2341/12-484-L

14. Van Ende A, De Munck J, Lise DP, Van Meerbeek B. Bulk-fill composites: a review of the current literature. J Adhes Dent. 2017;19(2):95-109. https://doi.org/10.3290/i.jad.a38141

15. Miletic V, Marjanovic J, Veliovic DN, Stasic JN, Petrovic V. Color stability of bulk-fill and universal composite restorations with dissimilar dentin replacement materials. J Esthet Restor Dent. 2019 Sep;31(5):520-8. https://doi.org/10.1111/jerd.12529

16. Garoushi S, Vallittu P, Shinya A, Lassila L. Influence of increment thickness on light transmission, degree of conversion and micro hardness of bulk fill composites. Odontology. 2016 Sep;104(3):291-7. https://doi.org/10.1007/s10266-015-0227-0

17. Al-Ahdal K, llie N, Silikas N, Watts DC. Polymerization kinetics and impact of post polymerization on the Degree of Conversion of bulk-fill resin-composite at clinically relevant depth. Dent Mater. 2015 Oct;31(10):1207-13. https://doi.org/10.1016/i.dental.2015.07.004

18. Cebe MA, Cebe F, Cengiz MF, Cetin AR, Arpag OF, Ozturk B. Elution of monomer from different bulk fill dental composite resins. Dent Mater. 2015 Jul;31(7):e141-9. https://doi.org/10.1016/i.dental.2015.04.008

19. Al-Harbi F, Kaisarly D, Bader D, El Gezawi M. Marginal integrity of bulk versus incremental fill class II composite restorations. Oper Dent. 2016 Mar-Apr;41(2):146-56. https://doi.org/10.2341/14-306-L

20. Price RB, Labrie D, Whalen JM, Felix CM. Effect of distance on irradiance and beam homogeneity from 4 light-emitting diode curing units. J Can Dent Assoc. 2011;77:b9.

21. Aromaa MK, Lassila LV, Vallittu PK. Effect of distance on light transmission through polymerized resin composite. Eur J Prosthodont Restor Dent. 2017 Sep;25(3):131-5. https://doi.org/10.1922/EJPRD_01700Aromaa05 
- Color stability of a bulk-fill composite resin light-cured at different distances

22. Commission Internationale del Éclairage.Colorimetry. Vienna: CIE Central Bureau, 2004. (CIE Technical Report, n. 15.3).

23. Paravina RD, Ghinea R, Herrera LJ, Bona AD, Igiel C, Linninger M, et al. Color difference thresholds in dentistry. J Esthet Restor Dent. 2015 Mar-Apr;27 Suppl 1:S1-9. https://doi.org/10.1111/jerd.12149

24. International Organization for Standardization - ISO. ISO/TR 28642: 2016. Technical Report (E): Dentistry; guidance on colour measurements. Geneva: ISO; 2016.

25. Sharma G, Wu W, Dalal EN. The CIEDE2000 color-difference formula: implementation notes, supplementary test data, and mathematical observations. Color Res Appl. 2005 Feb;30(1):21-30. https://doi.org/10.1002/col.20070.

26. Pérez MM, Ghinea R, Rivas MJ, Yebra A, lonescu AM, Paravina RD, et al. Development of a customized whiteness index for dentistry based on CIELAB color space. Dent Mater. 2016 Mar;32(3):461-7. https://doi.org/10.1016/i.dental.2015.12.008

27. Pérez MM, Herrera LJ, Carrillo F, Pecho OE, Dudea D, Gasparik C, et al. Whiteness difference thresholds in dentistry. Dent Mater. 2019 Feb;35(2):292-7. https://doi.org/10.1016/i.dental.2018.11.022

28. R Core Team. R: a language and environment for statistical computing. Vienna: R Foundation for Statistical Computing; 2018.

29. Hervás-García A, Martínez-Lozano MA, Cabanes-Vila J, Barjau-Escribano A, Fos-Galve P. Composite resins: a review of the materials and clinical indications. Med Oral Patol Oral Cir Bucal. 2006 Mar;11(2):E215-20.

30. Schmeling M, Andrada MA, Maia HP, Araújo EM. Translucency of value resin composites used to replace enamel in stratified composite restoration techniques. J Esthet Restor Dent. 2012 Feb;24(1):53-8. https://doi.org/10.1111/j.1708-8240.2011.00419.x

31. Ferracane JL. Hygroscopic and hydrolytic effects in dental polymer networks. Dent Mater. 2006 Mar;22(3):211-22. https://doi.org/10.1016/i.dental.2005.05.005

32. Alshali RZ, Salim NA, Sung R, Satterthwaite JD, Silikas N. Analysis of long-term monomer elution from bulk-fill and conventional resin-composites using high performance liquid chromatography. Dent Mater. 2015 Dec;31(12):1587-98. https://doi.org/10.1016/i.dental.2015.10.006

33. Misilli T, Gönülol N. Water sorption and solubility of bulk-fill composites polymerized with a third generation LED LCU. Braz Oral Res. 2017 Sep;31(0):e80. https://doi.org/10.1590/1807-3107bor-2017.vol31.0080

34. Kalachandra S. Influence of fillers on the water sorption of composites. Dent Mater. 1989 Jul;5(4):283-8. https://doi.org/10.1016/0109-5641(89)90077-8

35. Mansouri SA, Zidan AZ. Effect of water sorption and solubility on color stability of bulk-fill resin composite. J Contemp Dent Pract. 2018 Sep;19(9):1129-34. https://doi.org/10.5005/ip-journals-10024-2393

36. Par M, Repusic I, Skenderovic H, Milat O, Spajic J, Tarle Z. The effects of extended curing time and radiant energy on microhardness and temperature rise of conventional and bulk-fill resin composites. Clin Oral Investig. 2019 Oct;23(10):3777-88. https://doi.org/10.1007/s00784-019-02807-1

37. Beolchi RS, Moura-Netto C, Palo RM, Rocha Gomes Torres C, Pelissier B. Changes in irradiance and energy density in relation to different curing distances. Braz Oral Res. 2015;29(1):S1806-83242015000100257. https://doi.org/10.1590/1807-3107BOR-2015.vol29.0060

38. Sampaio CS, Atria PJ, Rueggeberg FA, Yamaguchi S, Giannini M, Coelho PG, et al. Effect of blue and violet light on polymerization shrinkage vectors of a CQ/TPO-containing composite. Dent Mater. 2017 Jul;33(7):796-804. https://doi.org/10.1016/i.dental.2017.04.010

39. Zorzin J, Maier E, Harre S, Fey T, Belli R, Lohbaver U, et al. Bulk-fill resin composites: polymerization properties and extended light curing. Dent Mater. 2015 Mar;31(3):293-301. https://doi.org/10.1016/i.dental.2014.12.010 